\title{
Prevalence and predictors of urinary tract infection in full-term and preterm neonates
}

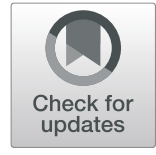

Wael Mohamed ${ }^{*}$ (D, Alkassem Algameel, Rasha Bassyouni and Abd el Tawab Mahmoud

\begin{abstract}
Background: Early and prompt diagnosis of urinary tract infection (UTI) in neonates has important therapeutic implications. The aim of this study was to evaluate the prevalence of UTI in neonates admitted to a referral neonatal intensive care unit (NICU) and to identify predictors associated with an increased risk of UTI in NICU population.

Results: The prevalence of culture-proven UTI in the studied neonates was 6.67\%. Moreover, UTI was more frequent (70\%) among full-term neonates. Additionally, both fever and pyuria were the only clinical and laboratory findings that showed significant association with UTI $(p<0.05)$. Binary logistic regression revealed that neonates with pyuria in urine analysis were 5.44 times more liable to have UTI, while the presence of fever constitutes a risk of only 0.166 (odds ratios were 5.44 and 0.166 , respectively). Additionally, sensitivity, specificity, positive predictive value, and negative predictive value of the regression model were 50.0, 94.5, 20.05, and 98.57\%, respectively.

Conclusions: We conclude that UTI is not uncommon in full-term neonates admitted in NICU. Additionally, pyuria was significantly related to positive urine culture and its detection in urine analysis increases the likelihood of UTI by 5.44 times.
\end{abstract}

Keywords: Neonates, Pyuria, Urine culture, UTI, NICU

\section{Background}

Urinary tract is a common site of infection in infants and young children. Prevalence of urinary tract infection (UTI) among full-term neonates has been reported to be up to $1.1 \%$. This figure increased up to $7 \%$ among those with fever [1], whereas the incidence of neonatal UTI varies from 0.1 to $1 \%$ of all infants. This rate increases to 10.7 and $15.4 \%$ in febrile infants younger than 30 days [2].

Compared to full-term neonates, the overall occurrence of UTI is reported higher in preterm. However, the true prevalence of UTI in preterm neonates is difficult to determine, as sterile urine cultures are not reliably obtained in all suspected sepsis assessments. The assumed complications of sterile catheterization or suprapubic aspiration hinder urine collection, and

\footnotetext{
* Correspondence: wsmohamed1234@gmail.com

Pediatrics Department, Faculty of Medicine, Fayoum University, Al Fayoum,
} Egypt

alternative collection methods such as bag collection he high rates of contamination [3].

Characterization of UTI in neonates is very essential. It may be the first indicator of underlying abnoranomalies [4].

A study of 45 male infants with a first UTI renal ultracollecting system, posterior urethral valves, ureteropelvic junction stricture, and renal atrophy and scarring [5]. Another study revealed that $47 \%$ of febrile infants less than 30 days of age with a UTI had renal abnormalities, most of them hydronephrosis (27\%) and pelviectasis 
(20\%). However, in infants with UTI who showed no abnormalities in ultrasound and voiding cystourethrogram, DMSA scan showed renal cortical damage [6]. Moreover, antenatal hydronephrosis is a common finding on prenatal ultrasonography. Up to $20 \%$ of infants with antenatal hydronephrosis have vesicoureteral reflux. There is a controversy regarding the association between $\mathrm{ANH}$ and the increased risk of recurrent UTIs in children [7].

Furthermore, correct identification of UTI in the neonate has important therapeutic implications, where rapid diagnosis and beginning of treatment prevents long-term renal complications such as renal parenchymal scarring and chronic kidney disease [2].

There are no established clear guidelines for the management of UTI in neonates. Hence, many clinicians apply the American Academy of Pediatrics (AAP) practice parameter for young children aged 2-24 months, which recommends 7-14 days of antimicrobial therapy for complete cure of UTI [8]. Additionally, the Guidelines of the European Association of Urology (EAU) for pediatric urology has recommended parenteral antibiotic therapy for UTI in newborns and infants aged less than 2 months [9]. Likewise, intravenous (IV) antibiotics have been recommended in infants younger than 3 months with a possible UTI by the National Institute for Health and Care Excellence (NICE) guidelines [10].

The ability to identify patients in the neonatal intensive care unit who are at increased risk for UTI would help ensure that those patients have urine cultures [11]. In the very low-birth-weight neonates, UTI was associated with higher cholestasis, higher central line and parenteral nutrition days, prolonged mechanical ventilation, and chronic lung disease [12]. Yet, it is unclear whether these risk factors are the same for full-term neonates.

Therefore, the aim of this study was to evaluate the prevalence of UTI in neonates admitted to a referral NICU and to identify clinical and/or laboratory predictors that are associated with an increased risk of UTI in NICU population.

\section{Methods}

\section{Study design and settings}

This cross-sectional study was conducted at Abshawai District Hospital, Fayoum Governorate, Egypt, during the period from October 2016 to October 2017. This study was reviewed by the Faculty of Medicine Research Ethical Committee. Participants were informed about the objectives of the study, the examination, and the investigations to be done. Confidentiality of their information was maintained and their right not to participate in the study was ensured.

\section{Eligibility criteria}

All consecutive male and female full-term (gestational age $\geq 37$ weeks) or preterm neonates (gestational age <
37 weeks) admitted to the NICU were included. Neonate presenting with major congenital anomalies and those whose parents refused to be enrolled in the study were excluded.

\section{Data collection}

The recruited patients were subjected to full historytaking including prenatal, natal (particularly mode, place, and complications of delivery; birth weight; first cry; and conditions at birth), and postnatal history (symptoms suggestive of UTI including non-specific symptoms, such as fever, hypothermia, vomiting, poor suckling, and irritability or lethargy, and /or specific symptoms, such as urine retention, anuria, and abnormalities in the urine stream or flow of urine).

Each neonate was examined generally and locally to assess his state of consciousness, weight, complexion, and vital signs. Abdominal examination (for tenderness, renal mass, hepatomegaly, or splenomegaly) and neurological examination (eliciting suckling and Moro reflexes) were carried out.

Each case was subjected to complete urine analysis and urine culture of uncentrifuged urine and colony count detection. Urine samples were collected using suprapubic bladder aspirate technique according to Robinson et al. [13].

Technique of suprapubic bladder aspirate: Proper cleansing of suprapubic region using alcohol followed by washing with sterile water was carried out, then a $10-\mathrm{ml}$ syringe with 21-gauge needle was introduced perpendicularly 1 fingerbreadth above the symphysis pubis under ultrasound guidance. When the needle was just subcutaneous, a suction force was exerted on introduction. When 1-2 $\mathrm{ml}$ urine was obtained, the needle was withdrawn and a sterile gauze was applied on the skin. If this trial failed, a second trial was done within $20-30$ min after a feed. This technique was used because clean urine collection by noninvasive techniques was not possible.

Urinary tract infection was diagnosed based upon positive urine culture. Growth of $\geq 100.000$ of colony-forming units (CFUs) per $\mathrm{mL}$ of a single type uropathogen was considered positive, whereas mixed growth was not diagnosed as UTI. Regarding urine analysis, it was not tested for nitrites, pyuria was defined as presence of $>5$ white blood cells per high-power field, and hematuria by the presence of $>5$ red blood cells per high-power field.

\section{Statistical analysis}

Data analysis was carried out using SPSS version 22. All numerical variables were checked for normality by Shapiro-Wilk test. They were abnormally distributed and were expressed as median and interquartile range (25th-75th percentile), and the differences between the two groups were tested using Mann-Whitney test. Categorical variables were summarized as frequencies and 
percentages, and associations between variables were tested using Pearson's chi-square for independence with continuity correction which was computed for $2 \times 2$ tables. When the expected cell sizes less than 5, Fisher exact tests were applied. A binary logistic regression analysis was performed to determine the independent predictors of UTI. A $p$ value of $<0.05$ was considered statistically significant.

\section{Results}

This study was conducted on 150 newborns admitted to NICU who fulfilled the eligibility criteria during the study period. The age of the neonates ranged from 3 to 28 days with a median of 13 days (IQR $=6-20$ ). More than half $(54 \%)$ were males. Their weight ranged from 1400 to $2750 \mathrm{~g}$ with a median of $2685 \mathrm{~g}$. The majority (75\%) of them were full-term, and only 36 (24\%) gave history of positive consanguinity (Table 1).

Frequency of clinical manifestations were illustrated in Table 2. Fever, hypothermia, tachycardia, and tachypnea were found in $6,4,20$, and $22.7 \%$ of participants, respectively. Additionally, few of them showed jaundice and pallor (15.3 and 20\%, respectively), whereas, about one third showed vomiting and abdominal distension. Neurological examination revealed irritability, lethargy, poor suckling, and poor Moro reflex in 14.7, 24.0, 38.7, and $30.7 \%$, respectively, of the study participants.

Table 3 demonstrates results of urine analysis and culture of the studied neonates. Urine showed pyuria (14.7\%), hematuria (15.3\%), and calcium oxalate crystals (26.7\%) by microscopic examination. Urine culture was

Table 1 Demographic characteristics of the studied cases

\begin{tabular}{|c|c|c|c|}
\hline \multirow[t]{3}{*}{ Age (days) } & \multicolumn{2}{|c|}{ Minimum-maximum } & $1-28$ \\
\hline & \multicolumn{2}{|c|}{ Median } & 13 \\
\hline & \multicolumn{2}{|l|}{ IQR } & $6-20$ \\
\hline \multirow[t]{3}{*}{ Weight (g) } & \multicolumn{2}{|c|}{ Minimum-maximum } & $1400.0-27500.0$ \\
\hline & \multicolumn{2}{|l|}{ Median } & 2685.0 \\
\hline & \multicolumn{2}{|l|}{ IQR } & $1950.0-3000.0$ \\
\hline \multirow[t]{4}{*}{ Sex } & \multirow[t]{2}{*}{ Female } & $N$ & 69 \\
\hline & & $\%$ & 46.0 \\
\hline & \multirow[t]{2}{*}{ Male } & $N$ & 81 \\
\hline & & $\%$ & 54.0 \\
\hline \multirow[t]{4}{*}{ Maturity } & \multirow[t]{2}{*}{ Full-term } & $N$ & 113 \\
\hline & & $\%$ & 75.3 \\
\hline & \multirow[t]{2}{*}{ Preterm } & $N$ & 37 \\
\hline & & $\%$ & 24.7 \\
\hline \multirow[t]{4}{*}{ Consanguinity } & \multirow[t]{2}{*}{ No } & N & 114 \\
\hline & & $\%$ & 76.0 \\
\hline & \multirow[t]{2}{*}{ Yes } & N & 36 \\
\hline & & $\%$ & 24.0 \\
\hline
\end{tabular}

Table 2 Vital signs and clinical manifestations of the studied cases

\begin{tabular}{|c|c|c|c|}
\hline & & $N$ & $\%$ \\
\hline \multirow[t]{2}{*}{ Fever } & No & 141 & 94.0 \\
\hline & Yes & 9 & 6.0 \\
\hline \multirow[t]{2}{*}{ Hypothermia } & No & 144 & 96.0 \\
\hline & Yes & 6 & 4.0 \\
\hline \multirow[t]{2}{*}{ Pulse } & Normal & 120 & 80.0 \\
\hline & Tachycardia & 30 & 20.0 \\
\hline \multirow[t]{2}{*}{ Respiratory rate } & Normal & 116 & 77.3 \\
\hline & Tachypnea & 34 & 22.7 \\
\hline \multirow[t]{2}{*}{ Pallor } & No & 120 & 80.0 \\
\hline & Yes & 30 & 20.0 \\
\hline \multirow[t]{2}{*}{ Jaundice } & No & 127 & 84.7 \\
\hline & Yes & 23 & 15.3 \\
\hline \multirow[t]{2}{*}{ Cyanosis } & No & 149 & 99.3 \\
\hline & Yes & 1 & 0.7 \\
\hline \multirow[t]{2}{*}{ Vomiting } & No & 94 & 62.7 \\
\hline & Yes & 56 & 37.3 \\
\hline \multirow[t]{2}{*}{ Abdominal distension } & No & 95 & 63.3 \\
\hline & Yes & 55 & 36.7 \\
\hline \multirow[t]{2}{*}{ Umbilical inflammation } & No & 134 & 89.3 \\
\hline & Yes & 16 & 10.7 \\
\hline \multirow[t]{2}{*}{ Irritability } & No & 128 & 85.3 \\
\hline & Yes & 22 & 14.7 \\
\hline \multirow[t]{2}{*}{ Lethargy } & No & 114 & 76.0 \\
\hline & Yes & 36 & 24.0 \\
\hline \multirow[t]{2}{*}{ Convulsion } & No & 132 & 88.0 \\
\hline & Yes & 18 & 12.0 \\
\hline \multirow[t]{2}{*}{ Suckling } & Normal & 92 & 61.3 \\
\hline & Poor & 58 & 38.7 \\
\hline \multirow[t]{2}{*}{ Moro reflex } & Normal & 104 & 69.3 \\
\hline & Poor & 46 & 30.7 \\
\hline
\end{tabular}

Table 3 Urine analysis and culture of the studied cases

\begin{tabular}{llll}
\hline & & N & $\%$ \\
\hline Pyuria & Yes & 22 & 14.7 \\
& No & 128 & 85.3 \\
RBCS $>$ 5/HPF & Yes & 23 & 15.3 \\
& No & 127 & 84.7 \\
Crystals & Calcium oxalate & 40 & 26.7 \\
& Nil & 110 & 73.3 \\
Amorphous materials & Yes & 80 & 53.3 \\
& Nil & 70 & 46.7 \\
Growth in urine culture & No & 140 & 93.3 \\
& Yes & 10 & 6.7 \\
\hline
\end{tabular}


positive in $10(6.7 \%)$ out of 150 total patients, and Escherichia coli was the most frequently (60\%) detected microorganism. According to results of urine culture, UTI was documented in $6.67 \%$ of the studied neonates, and it was non-significantly more common (70\%) among full-term neonates $(p=0.71)$

There was no significant association between demographic characteristics, maturity, and consanguinity and urinary tract infection as demonstrated in Table 4. Furthermore, fever was the only clinical sign that showed significant association with UTI $(p=0.015)$ as shown in Table 5.

Table 6 shows that pyuria was the only laboratory finding in urine analysis that showed significant association with UTI $(p=0.007)$. The number of pus cells was significantly higher among patients with UTI (50 versus 12.2\%). There were 22 patients that showed pyuria, and only 5 of them showed positive urine culture.

Binomial logistic regression analysis model for prediction of UTI in neonates by fever and pyuria showed significant model with 93.3\% accuracy and sensitivity, specificity, positive predictive value, and negative predictive value of 50.0, 94.5, 20.0, and 98.57\%, respectively. Both fever and pyuria contributed to diagnosis of UTI $\left(R^{2}\right)$ by $18.9 \%$. The risk of developing UTI was 5.44 times higher in neonates that showed pyuria in urine analysis (odds ratio $=5.44$ ), while the presence of fever constituted a lower risk (odds ratio $=0.166$ ) (Table 7).*Significant at $p<0.05$

\section{Discussion}

This study demonstrated that the prevalence of cultureproven UTI in neonates was $6.67 \%$. Urinary tract infection was non-significantly more frequent (70\%) among full-term neonates. Moreover, both fever and pyuria were the only findings that showed significant association with UTI. Neonates that showed pyuria in urine analysis were 5.44 times more likely to have UTI, while the presence of fever constituted a risk of only 0.166.

In the present study, the prevalence of culture-proven UTI in neonates admitted to NICU was $6.67 \%$. In comparison, lower incidence (1-2.4\%) of UTI was reported among asymptomatic term neonates who were not admitted to NICU [14]. Additionally, our study revealed that the rate of UTI was non-significantly higher among fullterm neonates. In contrast, Mohseny et al. [3] reported a high risk (11.3\%) of UTI in NICU-admitted premature infants (less than 32 weeks) with central line and suspected sepsis. They attributed this high frequency to the presence of many risk factors for infection in preterm neonates.

The most commonly isolated organism in this study was $E$. coli. There were no fungal organisms isolated in

Table 4 Association of demographic characteristics, maturity, consanguinity, and urinary tract infection

\begin{tabular}{|c|c|c|c|c|c|c|}
\hline & & & \multicolumn{2}{|l|}{ UTI } & \multirow[b]{2}{*}{ Test statistic } & \multirow[b]{2}{*}{$p$ value } \\
\hline & & & Yes & No & & \\
\hline \multirow[t]{4}{*}{ Age } & \multicolumn{2}{|c|}{ Minimum-maximum } & $1-28$ & $1-28$ & 0.290 & 0.772 \\
\hline & \multicolumn{2}{|l|}{ Median } & 11 & 13 & & \\
\hline & \multicolumn{2}{|l|}{ IQR } & $4-20$ & $6-20$ & & \\
\hline & \multicolumn{2}{|l|}{ Mean rank } & 71.65 & 75.78 & & \\
\hline \multirow[t]{4}{*}{ Weight } & \multicolumn{2}{|c|}{ Minimum-maximum } & $1500.0-3250.0$ & $1400.0-2750.0$ & 0.569 & 0.569 \\
\hline & \multicolumn{2}{|l|}{ Median } & 2870.0 & 2675.0 & & \\
\hline & \multicolumn{2}{|l|}{ IQR } & $2590.0-3000.0$ & $1875.0-3000.0$ & & \\
\hline & \multicolumn{2}{|l|}{ Mean rank } & 83.05 & 74.69 & & \\
\hline \multirow[t]{4}{*}{ Sex } & \multirow[t]{2}{*}{ Female } & $N$ & 4 & 65 & 0.155 & 0.754 \\
\hline & & $\%$ & 40.0 & 46.4 & & \\
\hline & \multirow[t]{2}{*}{ Male } & $N$ & 6 & 75 & & \\
\hline & & $\%$ & 60.0 & 53.6 & & \\
\hline \multirow[t]{4}{*}{ Maturity } & \multirow[t]{2}{*}{ Full-term } & $N$ & 7 & 106 & 0.164 & 0.709 \\
\hline & & $\%$ & 70.0 & 75.7 & & \\
\hline & \multirow[t]{2}{*}{ Preterm } & $N$ & 3 & 34 & & \\
\hline & & $\%$ & 30.0 & 24.3 & & \\
\hline \multirow[t]{4}{*}{ Consanguinity } & \multirow[t]{2}{*}{ No } & $N$ & 8 & 106 & 0.09 & 1.0 \\
\hline & & $\%$ & 80.0 & 75.7 & & \\
\hline & \multirow[t]{2}{*}{ Yes } & $N$ & 2 & 34 & & \\
\hline & & $\%$ & 20.0 & 24.3 & & \\
\hline
\end{tabular}


Table 5 Association of clinical manifestations and urinary tract infection

\begin{tabular}{|c|c|c|c|c|c|c|c|}
\hline & & \multicolumn{4}{|c|}{ UTI } & \multirow[b]{3}{*}{$x^{2}$} & \multirow[b]{3}{*}{$p$ value } \\
\hline & & \multicolumn{2}{|c|}{ Yes } & \multicolumn{2}{|l|}{ No } & & \\
\hline & & $\bar{N}$ & $\%$ & $\bar{N}$ & $\%$ & & \\
\hline \multirow[t]{2}{*}{ Fever } & No & 7 & 70.0 & 134 & 95.7 & $6.85^{\mathrm{a}}$ & $0.009^{*}$ \\
\hline & Yes & 3 & 30.0 & 6 & 4.3 & & \\
\hline \multirow[t]{2}{*}{ Hypothermia } & No & 10 & 100.0 & 134 & 95.7 & 0.446 & 0.540 \\
\hline & Yes & 0 & 0.0 & 6 & 4.3 & & \\
\hline \multirow[t]{2}{*}{ Pulse } & Normal & 6 & 60.0 & 114 & 81.4 & 0.670 & 0.419 \\
\hline & Tachycardia & 4 & 40.0 & 26 & 18.6 & & \\
\hline \multirow[t]{2}{*}{ Respiratory rate } & Normal & 6 & 60.0 & 110 & 78.6 & 1.83 & 0.236 \\
\hline & Tachypnea & 4 & 40.0 & 30 & 21.4 & & \\
\hline \multirow[t]{2}{*}{ Pallor } & No & 7 & 70.0 & 113 & 80.7 & 0.670 & 0.687 \\
\hline & Yes & 3 & 30.0 & 27 & 19.3 & & \\
\hline \multirow[t]{2}{*}{ Jaundice } & No & 8 & 80.0 & 119 & 85.0 & 0.180 & 0.651 \\
\hline & Yes & 2 & 20.0 & 21 & 15.0 & & \\
\hline \multirow[t]{2}{*}{ Cyanosis } & No & 9 & 90.0 & 140 & 100.0 & 0.342 & 0.067 \\
\hline & Yes & 1 & 10.0 & 0 & 0.0 & & \\
\hline \multirow[t]{2}{*}{ Vomiting } & No & 8 & 80.0 & 86 & 61.4 & 1.37 & 0.322 \\
\hline & Yes & 2 & 20.0 & 54 & 38.6 & & \\
\hline \multirow[t]{2}{*}{ Abdominal distension } & No & 6 & 60.0 & 89 & 63.6 & 0.051 & 1.0 \\
\hline & Yes & 4 & 40.0 & 51 & 36.4 & & \\
\hline \multirow[t]{2}{*}{ Umbilical inflammation } & No & 8 & 80.0 & 126 & 90.0 & 0.979 & 0.601 \\
\hline & Yes & 2 & 20.0 & 14 & 10.0 & & \\
\hline \multirow[t]{2}{*}{ Irritability } & No & 7 & 70.0 & 121 & 86.4 & 2.013 & 0.165 \\
\hline & Yes & 3 & 30.0 & 19 & 13.6 & & \\
\hline \multirow[t]{2}{*}{ Lethargy } & No & 8 & 80.0 & 106 & 75.7 & 0.094 & 0.759 \\
\hline & Yes & 2 & 20.0 & 34 & 24.3 & & \\
\hline \multirow[t]{2}{*}{ Convulsion } & No & 9 & 90.0 & 123 & 87.9 & 0.041 & 0.840 \\
\hline & Yes & 1 & 10.0 & 17 & 12.1 & & \\
\hline \multirow[t]{2}{*}{ Suckling } & Normal & 6 & 60.0 & 86 & 61.4 & 0.008 & 0.929 \\
\hline & Poor & 4 & 40.0 & 54 & 38.6 & & \\
\hline \multirow[t]{2}{*}{ Moro reflex } & Normal & 6 & 60.0 & 98 & 70.0 & 0.439 & 0.805 \\
\hline & Poor & 4 & 40.0 & 42 & 30.0 & & \\
\hline
\end{tabular}

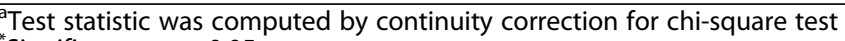

*Significant at $p<0.05$

Table 6 Association of urine analysis findings and urinary tract infection

\begin{tabular}{|c|c|c|c|c|c|c|c|}
\hline & & \multicolumn{4}{|c|}{ UTI } & \multirow[b]{3}{*}{$x^{2}$} & \multirow[b]{3}{*}{$p$ value } \\
\hline & & \multicolumn{2}{|c|}{ Yes } & \multicolumn{2}{|l|}{$\mathrm{No}$} & & \\
\hline & & $\bar{N}$ & $\%$ & $\bar{N}$ & $\%$ & & \\
\hline \multirow[t]{2}{*}{ Pyuria } & Yes & 5 & 50.0 & 17 & 12.1 & 10.68 & $0.007^{*}$ \\
\hline & No & 5 & 50.0 & 123 & 87.9 & & \\
\hline \multirow[t]{2}{*}{$\mathrm{RBCS}>5 / \mathrm{HPF}$} & Yes & 3 & 30.0 & 20 & 14.3 & 1.77 & 0.183 \\
\hline & No & 7 & 70.0 & 120 & 85.7 & & \\
\hline \multirow[t]{2}{*}{ Crystals } & Calcium oxalate & 5 & 50.0 & 35 & 25.0 & 2.98 & 0.132 \\
\hline & $\mathrm{Nil}$ & 5 & 50.0 & 105 & 75.0 & & \\
\hline \multirow[t]{2}{*}{ Amorphous materials } & Yes & 8 & 80.0 & 72 & 51.4 & 3.06 & 0.105 \\
\hline & Nil & 2 & 20.0 & 68 & 48.6 & & \\
\hline
\end{tabular}


Table 7 Binomial logistic regression analysis model for prediction of UTI in neonates by fever and pyuria

\begin{tabular}{lllllllll}
\hline$R^{2}$ & Sensitivity & Specificity & Accuracy & Positive predictive value & Negative predictive value & Variables & Odds ratio & $p$ value \\
\hline $18.9 \%$ & $50.0 \%$ & $94.5 \%$ & $93.3 \%$ & $20.0 \%$ & $98.57 \%$ & Fever & 0.166 & $0.040^{*}$ \\
& & & & & Pyuria & 5.448 & $0.019^{*}$ \\
\hline
\end{tabular}

*Significant at $p<0.05$

culture. These results are in agreement with Tamim et al. [15] who have reported E. coli and Klebsiella sp. as the most commonly isolated species from urine culture of nosocomial UTI in NICU patients. On the other hand, an earlier study reported a higher proportion of hospital-acquired UTI caused by Candida sp. [16]. A lower average gestational age and lower average birth weight than our population explains this difference in the isolated pathogen [17].

Urinary tract infection is an important cause of serious bacterial infection in neonates, affecting 1 in 3 babies with proven bacterial infection [18]. Neonatal infections present with non-specific signs. In some cases, the diagnosis is not clearly established. This is particularly true for UTI, where there are no direct symptoms related to the urinary tract [19] Pyuria has been recognized as a sign of urinary infection in neonate. However, there is no distinct cutoff of the number of pus cells for establishing the diagnosis in suspected neonates [2]

Actually, the diagnostic validity of urine analysis is affected by many factors: first, sample collection technique like bag, catheter, or suprapubic sample; second, preparation of the specimen whether centrifuged or not; and third, the method of quantifying and reporting leukocytes per microscopic high-power field or per cubic millimeter. These differences have important consequences for the diagnostic and therapeutic management of neonates with suspected UTI [20].

In this study, the urine collected by suprapubic bladder aspirate technique revealed pyuria in $14.7 \%$ of the studied neonates. Comparable to our findings, a prospective study which included consecutive infants $<28$ days of age admitted to the NICU of Liaquat National Hospital, Karachi, reported a higher $(31.8 \%)$ incidence of pyuria [4]. This higher prevalence may be attributed to urine collection using urethral catheterization.

Furthermore, our study revealed that pyuria (> 5 cell/ hpf) was the only laboratory finding in urine analysis that showed significant association with UTI. Similarly, Rahman et al. [4] reported a significant relationship between any number of pus cells in urine and a positive culture. They showed that pyuria 1-9 cells/hpf was associated with positive urine culture. In contrast, most authors support pyuria of $<10 \mathrm{cell} / \mathrm{hpf}$ as being indicative of presence of low risk of bacterial infections [21, 22]. So, it seems that no clear consensus has been established regarding the cutoff number of pus cells in urine that should be considered abnormal.
Neonates have an immature immune system. Further, responses of uroepithelium have not been extensively studied in this age group. So, data supporting leucocyte urothelial responses are limited [17]. Consequently, the significance of pyuria as a screening tool remains controversial in this age group [4]. Some authors agree with the fact that the sensitivity and specificity of the urine analysis is low. Hence, urine analysis may miss a lot of cases of UTI in neonates especially in premature neonates.

Binary logistic regression analysis revealed a model consisting of both pyuria and fever for prediction of UTI with an accuracy of $93.3 \%$. It was noted that this regression model had a high specificity $(94.5 \%)$ and negative predictive value $(98.57 \%)$, while its sensitivity (50\%) and positive predictive value (20\%) was lower. Hence, the absence of pyuria and fever in a neonate excluded the diagnosis of UTI by $98.57 \%$, whereas in $20 \%$ of neonates the presence of both pyuria and fever confirmed the diagnosis of UTI. In comparison, Tzimenatos et al. [23] revealed that urine analysis was highly sensitive and specific (87 and 91\%) for the diagnosis of UTI in febrile infants 60 days or younger for UTIs with colony counts with $\geq 10000 \mathrm{CFUs} / \mathrm{mL}$. Furthermore, binary regression analysis has also revealed that neonates that showed pyuria in urine analysis were 5.44 times more likely to have UTI. On the other hand, the presence of fever constituted a risk of only 0.166 . The observed lower risk (odds ratio) of fever might be attributed to the higher frequency of pyuria than fever among UTI patients in our study (50 versus $30 \%$ ). Moreover, fever is a nonspecific manifestation that can be seen in neonatal sepsis and it is not specific to UTI [24].

This study is limited by lack of randomization and follow-up of patients.

\section{Conclusions}

Based on these findings, we conclude that UTI is not uncommon in full-term neonates admitted to NICU. Additionally, pyuria was significantly related to positive urine culture and its detection in urine analysis increases likelihood of UTI by 5.44 times, while the presence of fever was significantly associated with UTI with a lower risk rate of 0.166 . Urine analysis should be performed routinely in neonates admitted to NICU, and cultures should preferably be performed before the start of the antibiotic treatment. 


\section{Abbreviations}

UTI: Urinary tract infection; NICU: Neonatal intensive care unit; AAP: American Academy of Pediatrics

\section{Acknowledgements}

Not applicable

\section{Authors' contributions}

WM conceived and designed the study and participated in drafting the manuscript. AA participated in the design of the study and performed the statistical analysis. RB participated in the statistical analysis and helped to draft the manuscript. AM participated in the manuscript drafting and carried out the data collection. All authors read and approved the final manuscript.

\section{Funding}

Not applicable

\section{Availability of data and materials}

The datasets used and/or analyzed during the current study are available from the corresponding author on reasonable request.

\section{Ethics approval and consent to participate}

The study was approved by the Ethical Committee of the Faculty of Medicine, Fayoum University. Participants' guardians were informed about the objectives of the study and the required examination and investigations, and written consent was obtained from them. Confidentiality of the participants' data was maintained, and their right not to participate in the study was ensured (ethics committee's reference number: 23-13/03/2016)

\section{Consent for publication}

Not applicable

\section{Competing interests}

The authors declare that they have no competing interests.

Received: 8 July 2019 Accepted: 17 February 2020

Published online: 20 April 2020

\section{References}

1. Beetz R (2012) Evaluation and management of urinary tract infections in the neonate. Curr Opin Pediatr 24(2):205-211

2. Arshad $M$, Seed PC (2015) Urinary tract infections in the infant. Clin Perinatol 42(1):17-28 vii

3. Mohseny AB, van Velze V, Steggerda SJ et al (2018) Late-onset sepsis due to urinary tract infection in very preterm neonates is not uncommon. Eur Pediatr 177(1):33-38

4. Rahman AJ, Naz F, Ashraf S (2011) Significance of pyuria in the diagnosis of urinary tract infections in neonates. J Pak Med Assoc 61(1):70-73

5. Goldman M, Lahat E, Strauss $S$ et al (2000) Imaging after urinary tract infection in male neonates. Pediatrics 105(6):1232-1235

6. Bonadio W, Maida G (2014) Urinary tract infection in outpatient febrile infants younger than 30 days of age: a 10-year evaluation. Pediatr Infect Dis J 33(4):342-344

7. Moore SS, Bahat H, Rachmiel M et al (2015) Guidelines for urinary tract infections and antenatal hydronephrosis should be gender specific. Acta Paediatr 104(11):e512-e517

8. Roberts KB (2011) Urinary tract infection: clinical practice guideline for the diagnosis and management of the initial UTI in febrile infants and children 2 to 24 months. Pediatrics 128(3):595-610

9. Stein R, Dogan HS, Hoebeke P et al (2015) Urinary tract infections in children: EAU/ESPU guidelines. Eur Urol 67(3):546-558

10. Mori R, Lakhanpaul M, Verrier-Jones K et al (2007) Diagnosis and management of urinary tract infection in children: summary of NICE guidance. BMJ 335(7616):395-397

11. Cataldi L, Zaffanello M, Gnarra M et al (2010) Urinary tract infection in the newborn and the infant: state of the art. J Matern Fetal Neonatal Med 23(Suppl 3):90-93

12. Ruangkit C, Satpute A, Vogt BA et al (2016) Incidence and risk factors of urinary tract infection in very low birth weight infants. J Neonatal Perinatal Med 9(1):83-90
13. Robinson CA, Siu A, Meyers R (2014) Standard dose development for medications commonly used in the neonatal intensive care unit. J Pediatr Pharmacol Ther 19(2):118-126

14. Foglia $\mathrm{EE}$, Lorch SA (2012) Clinical predictors of urinary tract infection in the neonatal intensive care unit. J Neonatal Perinatal Med 5(4):327-333

15. Tamim MM, Alesseh $\mathrm{H}$, Aziz H (2003) Analysis of the efficacy of urine culture as part of sepsis evaluation in the premature infant. Pediatr Infect Dis J 22(9):805-808

16. Phillips JR, Karlowicz MG (1997) Prevalence of Candida species in hospitalacquired urinary tract infections in a neonatal intensive care unit. Pediatr Infect Dis J 16(2):190-194

17. Stoll BJ, Hansen N, Fanaroff AA et al (2002) Late-onset sepsis in very low birth weight neonates: the experience of the NICHD Neonatal Research Network. Pediatrics 110(2 Pt 1):285-291

18. An YK, Cho MH, Kim KS (2016) Which factors related to the renal cortical defects in infants under 3 months of age with urinary tract infections? Child Kidney Dis 20(2):57-62

19. Swerkersson S, Jodal U, Ahren C et al (2016) Urinary tract infection in infants: the significance of low bacterial count. Pediatr Nephrol 31(2):239245

20. Coutinho K, Stensland K, Akhavan A et al (2014) Pediatrician noncompliance with the American Academy of Pediatrics guidelines for the workup of UTI in infants. Clin Pediatr 53(12):1139-1148

21. Primack W, Bukowski T, Sutherland R et al (2017) What urinary colony count indicates a urinary tract infection in children? J Pediatr 191:259-61.e1

22. Hoberman A, Wald ER, Reynolds EA et al (1994) Pyuria and bacteriuria in urine specimens obtained by catheter from young children with fever. J Pediatr 124(4):513-519

23. Tzimenatos L, Mahajan P, Dayan PS et al (2018) Accuracy of the urinalysis for urinary tract infections in febrile infants 60 days and younger. Pediatrics 141(2)

24. Freedman SB, Al-Harthy N, Thull-Freedman J (2009) The crying infant: diagnostic testing and frequency of serious underlying disease. Pediatrics 123(3):841-848

\section{Publisher's Note}

Springer Nature remains neutral with regard to jurisdictional claims in published maps and institutional affiliations.

\section{Submit your manuscript to a SpringerOpen ${ }^{\circ}$ journal and benefit from:}

- Convenient online submission

- Rigorous peer review

- Open access: articles freely available online

- High visibility within the field

- Retaining the copyright to your article

Submit your next manuscript at $\boldsymbol{\nabla}$ springeropen.com 